Vietnam Journal of Mechanics, VAST, Vol. 43, No. 1 (2021), pp. 1-11

DOI: https://doi.org/10.15625/0866-7136/15054

\title{
THE EFFECT OF THE CHILLED WATER TEMPERATURE ON THE PERFORMANCE OF AN EXPERIMENTAL AIR-COOLED CHILLER
}

\author{
Phan Thi Thu Huong ${ }^{1,2}$, Hoang Mai Hong ${ }^{2}$, Lai Ngoc Anh ${ }^{1, *}$ \\ ${ }^{1}$ Hanoi University of Science and Technology, Hanoi, Vietnam \\ ${ }^{2}$ Nam Dinh University of Technology Education, Nam Dinh, Vietnam \\ *E-mail: anhngoclai@yahoo.com
}

Received: 11 May 2020 / Published online: 22 January 2021

\begin{abstract}
This paper presents the study results on the effect of the chilled water temperature on the coefficient of performance (COP) of an experimental air-cooled chiller. The measuring sensors and instrument were calibrated, and the uncertainty of the measuring temperature and pressure were evaluated. The uncertainty of measured temperature and pressure at $95 \%$ confidence level is $0.12{ }^{\circ} \mathrm{C}$ and $1.4 \mathrm{kPa}$, respectively. The isentropic compression efficiency and the COP of the air-cooled chiller operating at a condensation temperature of $48.05^{\circ} \mathrm{C}$ and evaporation temperature of $3.17^{\circ} \mathrm{C}$ are $63 \%$ and 2.69 , respectively. The chilled water temperature has a significant influence on evaporation pressure and the COP of the chiller. If the temperature of the air entering the condenser of the chiller is maintained at $35^{\circ} \mathrm{C}$, the COP of the chiller increases from 2.55 to 2.89 when the temperature of the chiller water increases only $4 \mathrm{~K}$, from $8{ }^{\circ} \mathrm{C}$ to $12{ }^{\circ} \mathrm{C}$.
\end{abstract}

Keywords: experimental set-up, air-cooled chiller, coefficient of performance COP, the temperature of chilled water.

\section{INTRODUCTION}

According to statistics, the population of the world is 7.59 billion [1]. The living standards of the people have been improved together with economic development. People's comfort demand has been increased. The requirements for the comfort conditions of the space, cold and hot drinking water are popular and the need for the use of heat pump and air-conditioner has been increased recently. The demands cover in all commercial and public buildings (such as office buildings, schools, hospitals, restaurants, hotels, museums, etc.) or private houses with a wide variety of energy-using equipment (HVAC, hot - cold water dispenser, domestic hot water, refrigerator, etc.). According to Lombard et al. [2], the energy consumption of air conditioning systems in buildings is about $50 \%$ of building consumption and $20 \%$ of a country's total consumption. Therefore, the study 
on the energy consumption and the issue of efficiency energy of the heat pump and air conditioning systems are useful and interesting.

The energy efficiency of the heat pump and air conditioning system can be evaluated with the coefficient of performance COP. In this study on the air-cooled water chiller, the COP is also used to evaluate the energy conversion efficiency of the chiller. Some studies have been carried out to enhance the reliability and energy efficiency of the water chiller system by implementing various improved control methods. These studies are carried out either for a separated component or for all components together. For example, in controlling separated component, Ma and Wang [3] presents the optimal control strategies for variable speed pumps with different configurations in a complex building equipped with air-conditioning systems to enhance their energy efficiencies, in which a sequence control strategy determines the optimal number of pumps in operation taking into account their power consumptions and maintenance costs. Some researchers have studied the optimal working conditions of the water chiller by simulating its components with specific characteristics and using algorithms to find the optimal operation modes of all components together. Yu et al. [4] implemented the random forest (RF) method to analyze the importance of operating variables on the COP of an air-cooled chiller and then predicted COP accurately. Most of these studies can optimally control refrigeration systems $[5,6]$. The above studies primarily demonstrated the potential energy savings associated with the optimal control in the water chiller system. However, these methods are quite complicated, and the procedure is carried out in bulky technical projects. Feasibility studies have been tested on simulation platforms. This study aims to develop a chilled water system for practical and real-time applications. In this study, the effect of the temperature of the chilled water on the COP of the chiller is investigated.

According to the author's knowledge, R134a is one of the most popular refrigerants used in refrigeration systems. It's accurate and reliable thermodynamic data are available. Besides, the supply for this refrigerant in domestic is abundant. Therefore, R134a was selected in this study for the evaluation of the experimental set-up as well as the investigation of the energy performance of the air-cooled chiller with the variation of the chilled water's temperature.

\section{EXPERIMENT SET-UP}

\subsection{Description of the experimental air-cooled chiller}

Schematic diagram of the experimental set-up is described in Fig. 1. The temperature and pressure of the refrigerant entering the compressor are measured by the temperature sensor T1 and the pressure sensor P1 (point 1). The temperature and pressure of the refrigerant at the compressor's outlet, point 2, are measured by the temperature sensor T2 and the pressure sensor P2. The state of the refrigerant R134a and its thermodynamic properties at the inlet and outlet of the compressor can be completely determined from the measured data. The temperature of R134a at the outlet of the condenser can be measured by sensor T3 (point 3). After passing through the receiver, the filter drier, the refrigerant R134a enters the capillary. The temperature and pressure of the R134a before

capillary, point 4 , are determined through the temperature sensor T4 and the pressure 
sensor P3. The temperature of the refrigerant R134a after capillary, point 5, is determined by the temperature sensor T5. The temperature of chilled water in the evaporator is determined by the temperature sensor $\mathrm{T}_{\text {water }}$ installed in the middle of the heat exchanger shell. Typical specifications of the compressor, condenser, capillary, and evaporator are shown in Tab. 1.

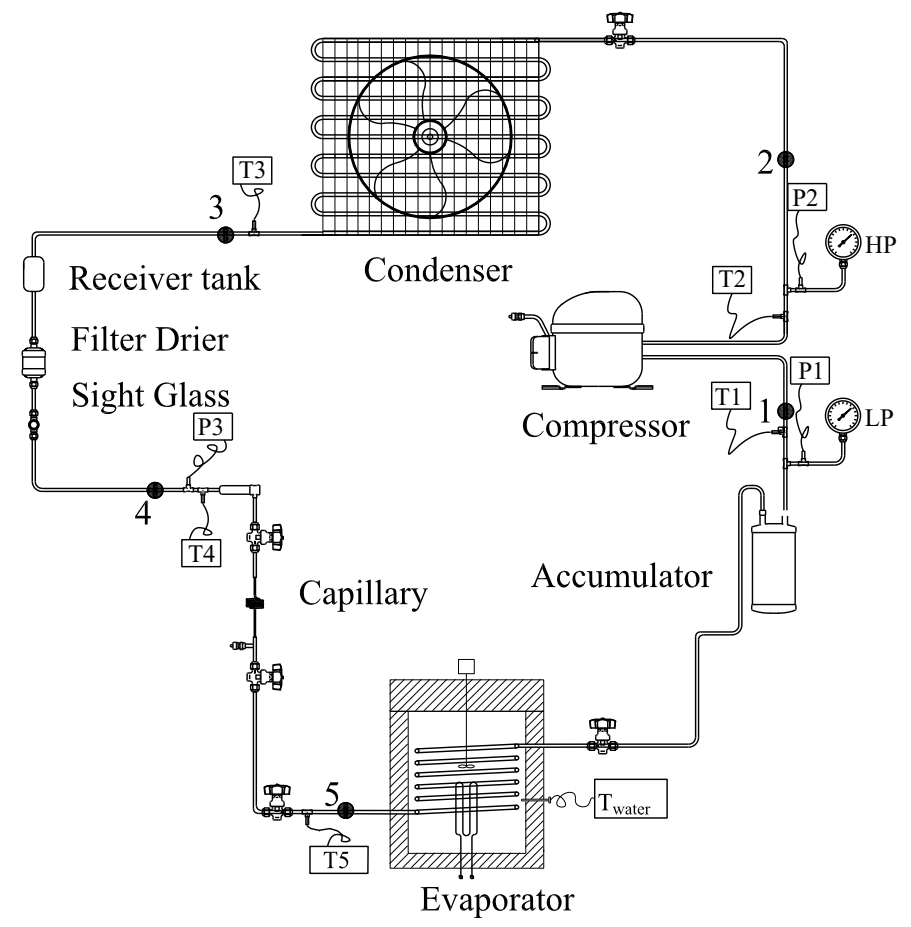

Fig. 1. Schematic diagram of the experimental air-cooled water chiller

Table 1. Typical specifications of the main equipment of the experimental set-up

\begin{tabular}{ll}
\hline Equipment & \multicolumn{1}{c}{ Specifications } \\
\hline Compressor & Closed piston compressor -1 phase \\
& Displacement: $8.37 \mathrm{cc} / \mathrm{rev}$ \\
\hline Condenser & Copper Steel Finned U Tube \\
& Air Cooled Heat Exchanger \\
& Heat exchanger area: $3.4 \mathrm{~m}^{2}$ \\
\hline Capillary & Copper pipe \\
& Inner diameter: $0.5-1.0 \mathrm{~mm}$ \\
\hline Evaporator & 1. Shell: 304 stainless steel \\
& 2. Spiral tube inside \\
& 3. Superlon insulation \\
& 4. Stirrer \\
\hline
\end{tabular}




\subsection{Determination of the energy characteristics of the main equipment and system}

The state of the refrigerant R134a as well as other caloric properties, e.g., enthalpy, can be determined from the measured temperature and measured pressure. The COP of the air-cooled chiller can't be measured directly. However, the COP can be calculated from the measured and calculated thermodynamic properties. Ignoring the pressure losses and the heat losses on piping and auxiliary equipment, energy performance of the main equipment and the whole system can be calculated from equations 1 to 6 as follow:

Reversible adiabatic work of the compression process $l_{i}$

$$
l_{i}=h_{1}-h_{2 s}, \quad \mathrm{~kJ} / \mathrm{kg}
$$

where $h_{2 s}$ is the enthalpy of the fluid after the compressor during adiabatic compression. $h_{2 s}$ is determined from the pressure $p_{2}$ of the fluid leaving the compressor and the entropy $s_{1}$ of the fluid entering the compressor. The value of enthalpy and entropy of all experimental points were determined by the Theproper software [7] through measured temperature and pressure.

The work of the compression process, the work of cycle, $l_{0}$

$$
l_{0}=h_{1}-h_{2}, \quad \mathrm{~kJ} / \mathrm{kg}
$$

The heat rejected by condenser $q_{k}$

$$
q_{k}=h_{3}-h_{2}, \mathrm{~kJ} / \mathrm{kg}
$$

where $h_{3}$ is the enthalpy of the fluid after the condenser. $h_{3}$ is determined from the temperature $t_{3}$ of the and pressure $p_{2}$ with the assumption that pressure loss though condenser is neglectable.

The heat absorbed by evaporator $q_{0}$

$$
q_{0}=h_{1}-h_{5}, \quad \mathrm{~kJ} / \mathrm{kg}
$$

where $h_{5}$ is the enthalpy of the fluid entering the evaporator. Under the assumption of the irreversible adiabatic throttling, $h_{5}$ is calculated to be equivalent to $h_{4}$ which determined from the measured temperature $t_{4}$ and measured pressure $p_{3}$.

The irreversible efficiency $\eta$ of the compression process

$$
\eta=l_{i} / l_{0}
$$

The coefficient of performance of the chiller

$$
\mathrm{COP}=q_{0} / l_{0} \text {. }
$$

\section{MEASUREMENT INSTRUMENT AND CALIBRATION}

The main objective of this study is to design and manufacture of a reliable experimental set-up and then to evaluate the performance of the air-cooled chiller experimentally. To obtain reliable experimental results measurement instruments must be calibrated. The error analysis was followed the TCVN 9595-3:2013 that identical to the ISO/IEC 
guide 98-3:2008, uncertainty of measurement - part 3: guide to the expression of uncertainty in measurement (GUM:1995). Temperature calibration was carried out according to "DLVN 138:2004 Digital and analog thermometers. Methods and means of calibration". Pressure calibration was carried out according to "DLVN 133:2004 Pressure switches. Methods and means of calibration". The evaluations of the uncertainty of the calibrated measurement instruments are given in following subsections.

\subsection{Data acquisition}

The system is equipped with a high-precision multi-channel data acquisition connected to a computer. The uncertainties of the measured values including the measurement error, switching error, and transducer conversion error are shown in Table 2. Advanced measurement features such as the offset compensation, variable integration time, and delay are also selectable on a per-channel basis. The voltage signals from the pressure sensors are collected by the data acquisition and then converted to pressure values through calibrated functions. The voltage signals from thermocouples are collected, and the temperature compensation is done automatically in the data acquisition. The indicated temperature is automatically converted to the standard ITS90 temperature scale. In this study, the temperature range is quite narrow. In order to improve the accuracy and reliability of measurement results, the complete temperature and pressure measurement instruments, including data acquisition, were calibrated by certified national calibration organization. Detail calibration information and uncertainty are given in next subsections.

Table 2. Specifications of the data acquisition unit

\begin{tabular}{ccc}
\hline Measurement parameters & Range & $\begin{array}{c}\text { Uncertainty } \\
\text { (\% of reading value }+\% \text { of range value) }\end{array}$ \\
\hline DC voltage & $100.0000 \mathrm{mV}$ & $0.0050+0.0040$ \\
& $1.0000 \mathrm{~V}$ & $0.0040+0.0007$ \\
& $10.0000 \mathrm{~V}$ & $0.0035+0.0005$ \\
\hline Thermocouples & & $1.2^{\circ} \mathrm{C}$ \\
$\mathrm{J}$ & $-150{ }^{\circ} \mathrm{C}$ to $1200{ }^{\circ} \mathrm{C}$ & $1.5^{\circ} \mathrm{C}$ \\
$\mathrm{K}$ & $-100{ }^{\circ} \mathrm{C}$ to $1200{ }^{\circ} \mathrm{C}$ & $1.5^{\circ} \mathrm{C}$ \\
\hline
\end{tabular}

\subsection{Calibrate temperature thermocouples and pressure sensors}

\subsubsection{Temperature calibration}

The interesting temperature range of this study is from $-40{ }^{\circ} \mathrm{C}$ to $120{ }^{\circ} \mathrm{C}$ so temperature measured with all thermocouples were calibrated for this range by using the calibration instruments of the national certified calibration organization, Tab. 3. The thermocouples are connected to the data acquisition unit through channels, the temperature values were read during the calibration process. After calibration, the uncertainty assessment has been conducted following TCVN 9595-3:2013, which is identical to the ISO/IEC 
Guide 98-3:2008 (GUM:1995) [8]. The uncertainties of the temperature measurement are listed in Tab. 4. The expanded largest uncertainty at 95\% confidence level of the measured temperature is $0.12{ }^{\circ} \mathrm{C}$. The data in Tabs. 3 and 5 prove that the uncertainty of temperature is improved significantly after calibration for the application range.

Table 3. Standard instruments for the calibration

\begin{tabular}{|c|c|c|}
\hline Device & Specifications & Applications \\
\hline $\begin{array}{c}\text { Standard Platinum } \\
\text { Resistance Thermometer }\end{array}$ & $\begin{array}{l}\text { Model: 5681; No: } 1496 \\
\text { Grand: Hart Scientific/USA } \\
\text { Range: }(-200 \sim 670){ }^{\circ} \mathrm{C} \\
\text { Uncertainty: } \mathrm{U}_{95}=0.002{ }^{\circ} \mathrm{C}\end{array}$ & $\begin{array}{c}\text { For calibration range } \\
\text { of }-40 \text { to } 120^{\circ} \mathrm{C}\end{array}$ \\
\hline $\begin{array}{l}\text { High Precision } \\
\text { thermometry Bridge }\end{array}$ & $\begin{array}{l}\text { Model: 1590; No: A11118 } \\
\text { Grand: Hart Scientific/USA } \\
\text { Range: }(-200 \sim 1070){ }^{\circ} \mathrm{C} \\
\text { Uncertainty: } \mathrm{U}_{95}=6 \mathrm{ppm}\end{array}$ & $\begin{array}{l}\text { For calibration range } \\
\text { of }-40 \text { to } 120^{\circ} \mathrm{C}\end{array}$ \\
\hline Liquid bath & $\begin{array}{l}\text { Model: } 7381 \text {; No: A4A020 } \\
\text { Grand: Hart Scientific/USA } \\
\text { Range: }(-80 \sim 110)^{\circ} \mathrm{C} \\
\text { Stability: } \pm 0.005{ }^{\circ} \mathrm{C} \\
\text { Axial Uniformity: } \pm 0.005^{\circ} \mathrm{C} \\
\text { Radial Uniformity: } \pm 0.005^{\circ} \mathrm{C}\end{array}$ & $\begin{array}{l}\text { For calibration range } \\
\text { of }-40 \text { to } 20{ }^{\circ} \mathrm{C}\end{array}$ \\
\hline Liquid bath & $\begin{array}{l}\text { Model: KB22; No: } 8203140 \\
\text { Grand: HETO/DENMARK } \\
\text { Range: }(-30 \sim 100)^{\circ} \mathrm{C} \\
\text { Stability: } \pm 0.005{ }^{\circ} \mathrm{C} \\
\text { Axial Uniformity: } \pm 0.005^{\circ} \mathrm{C} \\
\text { Radial Uniformity: } \pm 0.005^{\circ} \mathrm{C}\end{array}$ & $\begin{array}{c}\text { For calibration range } \\
\text { of } 20 \text { to } 70^{\circ} \mathrm{C}\end{array}$ \\
\hline Liquid bath & $\begin{array}{l}\text { Model: } 915 \mathrm{H} \text {; No: } 18915 / 1 \\
\text { Grand: ISOTECH/UK } \\
\text { Range: }(40 \sim 300)^{\circ} \mathrm{C} \\
\text { Stability: } \pm 0.005{ }^{\circ} \mathrm{C} \\
\text { Axial Uniformity: } \pm 0.005^{\circ} \mathrm{C} \\
\text { Radial Uniformity: } \pm 0.005{ }^{\circ} \mathrm{C} \text {; }\end{array}$ & $\begin{array}{l}\text { For calibration range } \\
\quad \text { of } 70 \text { to } 130{ }^{\circ} \mathrm{C}\end{array}$ \\
\hline
\end{tabular}

Table 4. The $\mathrm{U}_{95}$ extended uncertainty of temperature probes after calibration

\begin{tabular}{cccc}
\hline Thermocouple & Uncertainty $\mathrm{U}_{95}, \mathrm{~K}$ & Thermocouple & Uncertainty $\mathrm{U}_{95}, \mathrm{~K}$ \\
\hline $\mathrm{T} 1$ & 0.10 & $\mathrm{~T} 4$ & 0.08 \\
$\mathrm{~T} 2$ & 0.12 & $\mathrm{~T} 5$ & 0.05 \\
$\mathrm{~T} 3$ & 0.11 & $\mathrm{~T}_{\text {water }}$ & 0.12 \\
\hline
\end{tabular}

\subsubsection{Pressure calibration}

Similar to the temperature calibration, the pressure measurement instrument including sensors and data acquisition was connected to the computer to get measured voltage 
Table 5. Instruments used for the pressure calibration

\begin{tabular}{cl}
\hline \multicolumn{1}{c}{ Device } & \multicolumn{1}{c}{ Specifications } \\
\hline \multirow{3}{*}{ Calibration of vacuum pressure } & Model: 700PAS \\
& Range: 0-30 psi \\
& Uncertainty: 0.05\% \\
\hline \multirow{2}{*}{ Positive pressure calibration } & Model: Flux 701 and 700POS \\
& Uncertainty: 0.05\% \\
\cline { 2 - 2 } & Model: DPI 104 \\
& Range 0-70 bar (100 psi) \\
& Uncertainty: 0.05\% \\
& Model: DPI 140 \\
& Range: 0-200 bar \\
& Uncertainty: 0.05\% \\
&
\end{tabular}

and then converted to pressure values through the calibration functions. The pressure sensors were connected to the reference standard certified sensors used for calibration of the certified national calibration organization. Specifications of the standard reference calibration instruments of the certified national calibration organization are given in Tab. 5. After calibration, the maximum extension uncertainty $\mathrm{U}_{95}$ of the measured pressure values are $0.4 \%$, equivalent to $1.4 \mathrm{kPa}$.

\section{EXPERIMENTAL RESULTS AND EVALUATION}

In this study, refrigerant R134a is used to evaluate the new experimental set-up as well as to investigate the effect of the chilled water temperature on the energy performance of the air-cooled chiller. The reasons for choosing the refrigerant R134a are that the accurate thermodynamic properties of R134a are available and the supply of this refrigerant is abundant. The experimental temperature and pressure of typical points in the system in Fig. 1 were collected and then were used to calculate enthalpy by using the Theproper software [7]. In the Theproper, thermodynamic properties of the refrigerant R134a and other substances such as enthalpy are calculated from the Helmholtz energy function for the specific substance. The Helmholtz energy function is the explicit function of temperature and density. So, to calculate the enthalpy and other properties from the given temperature and pressure, an iteration loop with the variation of the density is done to find the calculated pressure. The iteration is stopped when the difference between the calculated pressure and the given pressure is smaller than a certain set error. At this state, the density is found from the given temperature and given pressure. The enthalpy then can be calculated from Eq. (7).

$$
\frac{h(\delta, \tau)}{R T}=1+\tau\left(\phi_{\tau}^{0}+\phi_{\tau}^{r}\right)+\delta \phi_{\delta}^{r}
$$


where $\delta=\rho / \rho_{c}, \tau=T_{c} / T$ and $\Phi=F /(R T)$. In which $\rho, T$, and $F$ are density, temperature, and the Helmholtz free energy function, respectively. The typical experimental measured data and the calculated enthalpy at a typical location are given in Tab. 6.

Table 6. Thermodynamic properties at typical points of the air-cooled water chiller

\begin{tabular}{cccc}
\hline $\begin{array}{c}\text { Location of } \\
\text { measured properties }\end{array}$ & $\begin{array}{c}\text { Measured temperature, } \\
{ }^{\circ} \mathrm{C}\end{array}$ & $\begin{array}{c}\text { Measured pressure, } \\
\mathrm{kPa}\end{array}$ & $\begin{array}{c}\text { Calculated Enthalpy, } \\
\mathrm{kJ} / \mathrm{kg}\end{array}$ \\
\hline Point 1 & 8.98 & 293 & 406.60 \\
Point 2 & 81.04 & 1362 & 458.23 \\
Point 3 & 48.05 & 1283 & 267.92 \\
Point 4 & 47.61 & & \\
Point 5 & 3.17 & & \\
Heat exchanger shell & 8.76 & & \\
\hline
\end{tabular}

The calculated enthalpy depends on the measured pressure and measured temperature, $h=h(t, p)$. The calculated enthalpy has uncertainty as the measured pressure and temperature have their own uncertainties. The uncertainty of the calculated enthalpy can be determined from the temperature uncertainty $u(t)$ and the pressure uncertainty $u(p)$. The enthalpy uncertainty can be calculated by $u(h)=h_{\max }-h_{\min }$. Where $h_{\max }=$ $h\left(t_{\max }, p_{\min }\right), h_{\min }=h\left(t_{\min }, p_{\max }\right), t_{\max }=t+u(t), t_{\min }=t-u(t), p_{\max }=p+u(p)$ and $p_{\min }=p-u(p)$. The temperature uncertainty is taken as the maximum uncertainty after the calibration of the temperature probe, $u(t)=0.21 \mathrm{~K}$. In the worst case there is no calibration, the maximum uncertainty is $1.5 \mathrm{~K}, \mathrm{Tab}$. 2 . The pressure uncertainty equal to the maximum uncertainty of the pressure probe, $u(p)=2.7 \mathrm{kPa}$. In this study, we test with the uncertainty of $5 \%$ of measured pressure, much higher than the calibrated pressure uncertainty. The uncertainty of the calculated enthalpy at a typically measured point are presented in Tab. 7. The results obtained from Tab. 7 show that the maximum enthalpy uncertainty is $5.39 \mathrm{~kJ} / \mathrm{kg}$, almost all within $1.18 \%$. The results show that enthalpy

Table 7. Uncertainty of calculated enthalpy at typical points of the refrigeration system

\begin{tabular}{cccc}
\hline Quantity & Entering compressor & Leaving compressor & Entering capillary \\
\hline $\mathrm{T},{ }^{\circ} \mathrm{C}$ & 8.98 & 81.04 & 47.61 \\
$\mathrm{p}, \mathrm{kPa}$ & 293 & 1362 & 1283 \\
$u(t)$ & 1.50 & 1.50 & 1.50 \\
$u(p)$ & 15 & 68 & 64 \\
$t_{\max }$ & 10.48 & 82.54 & 49.11 \\
$t_{\min }$ & 7.48 & 79.54 & 46.11 \\
$p_{\max }$ & 308 & 1430 & 1347 \\
$p_{\min }$ & 278 & 1294 & 1219 \\
$h(t, p), \mathrm{kJ} / \mathrm{kg}$ & 406.604 & 458.225 & 267.917 \\
$h_{\min }=h\left(t_{\min }, p_{\max }\right)$ & 404.88 & 455.50 & 265.59 \\
$h_{\max }=h\left(t_{\max }, p_{\min }\right)$ & 408.30 & 460.89 & 267.92 \\
$u(h)$ & 3.42 & 5.39 & 2.33 \\
$\% h$ & $0.84 \%$ & $1.18 \%$ & $0.87 \%$ \\
\hline
\end{tabular}


obtained from this study is accurate and reliable. The maximum enthalpy uncertainty for the case of temperature uncertainty of $0.21 \mathrm{~K}$ and pressure uncertainty of $2.7 \mathrm{kPa}$ is $0.49 \mathrm{~kJ} / \mathrm{kg}$, almost all within $0.14 \%$. Thus, the calculated energy exchange and energy performance of the air-cooled water chiller are reliable.

From the data in Tab. 6, the energy performance of all equipment and system can be determined with equations in Section 2.2. Example for the system operating at a condensation temperature of $48.05^{\circ} \mathrm{C}$ and evaporative temperature of $3.17{ }^{\circ} \mathrm{C}$ is 2.69 . In this operation, the cooling capacity and the non-reversible compression efficiency are $137.7 \mathrm{~kJ} / \mathrm{kg}$ and $63 \%$, respectively.

In practical, the temperature of the chilled water can have a significant effect on the energy performance of the system. The US normal requirement for space condition is $23^{\circ} \mathrm{C} \pm 2{ }^{\circ} \mathrm{C}$ and $55 \pm 5 \%$ RH. According to the "AHRI Standard 550/590 - 2015 [9], leaving chilled water temperature is $44^{\circ} \mathrm{F}\left(6.67^{\circ} \mathrm{C}\right)$, the return temperature is $54 \mathrm{~F}\left(12.22^{\circ} \mathrm{C}\right)$. In the airside, the $80 / 67^{\circ} \mathrm{F}(\mathrm{db} / \mathrm{wb})$ entering air condition and a $55 / 54.9^{\circ} \mathrm{F}$ leaving air condition is normally considered. The dew point temperature of the entering and leaving air are $15.76{ }^{\circ} \mathrm{C}$ and $12.72{ }^{\circ} \mathrm{C}$, correspondingly. The temperature difference between the water supply and dew point of the leaving air is $6.05 \mathrm{~K}$. For tropical climate like Vietnam, some experts and consultants advise setting the temperature of the room of $27{ }^{\circ} \mathrm{C}$ regardless of the relative humidity to save the energy consumption. Some cases advise the relative humidity of around $75 \%$. So, the temperature of the air entering the conditioned room can be $17^{\circ} \mathrm{C}$ or slightly higher. If the dehumidification is done with the $\mathrm{AHU}$, the dew point temperature can reach $17^{\circ} \mathrm{C}$ or even slightly higher. Thus, the chilled water temperature supply for the tropical climate can be around $11{ }^{\circ} \mathrm{C}$ or higher. So, in this study, the chilled water supply is considered up to $15.3^{\circ} \mathrm{C}$, much higher than the US rating standards. Moreover, to ensure the safety of the system, the operating mode at the water temperature lower than $6{ }^{\circ} \mathrm{C}$ is not studied. The end-user cares more about this temperature and the chilled water temperature is also used in the control strategy so this study investigates the effect of chilled water temperature on the energy performance of the air-cooled water chiller and the evaporator pressure. Fig. 2 shows the relationship

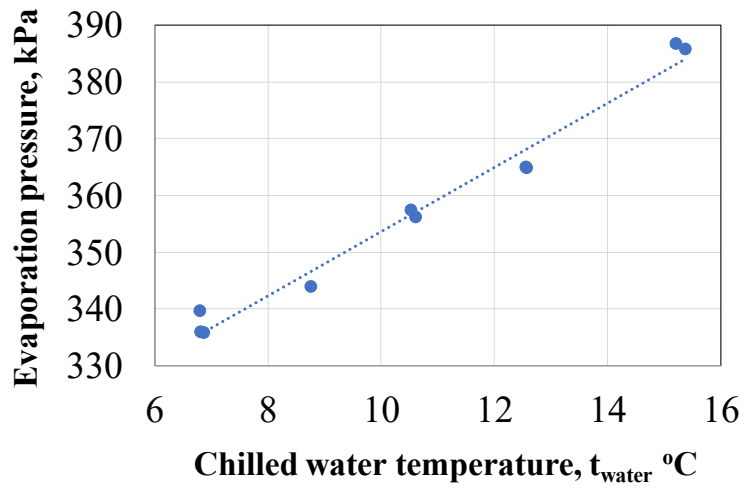

Fig. 2. Relationship between chilled water temperature and the evaporation pressure 
between chilled water temperature and the evaporation pressure of the air-cooled water chiller. When the temperature of the air entering the condenser is kept at $35^{\circ} \mathrm{C}$, the evaporation pressure increases together with the increase of the chilled water temperature, consequently the increase of energy conversion efficiency. When the chilled water temperature increases from $6.8^{\circ} \mathrm{C}$ to $15.3^{\circ} \mathrm{C}$, the evaporation pressure increased $43 \mathrm{kPa}$, equivalent to $12.42 \%$ compared to the evaporation pressure in the case with the chilled water temperature of $6.8^{\circ} \mathrm{C}$.

It is necessary to study the effect of the chilled water temperature on the energy conversion efficiency of the system. Fig. 3 shows the relationship between the chilled water temperature and the COP of the water chiller in the case that the temperature of the air entering the condenser is kept at $35{ }^{\circ} \mathrm{C}$, this is identical to the AHRI Standard $550 / 590-2015$ standard rating temperature of the ambient air entering the air-cooled chiller of $95 \mathrm{~F}$. The relationship between the COP and the chilled water temperature is shown in Eq. (8) with the goodness-of-fit measure for linear regression $R^{2}=0.97$. The high value of the $R$-squared proves a very strong relationship between the COP and the chilled water temperature.

$$
\mathrm{COP}=0.0843 * t_{\text {water }}+1.8771
$$

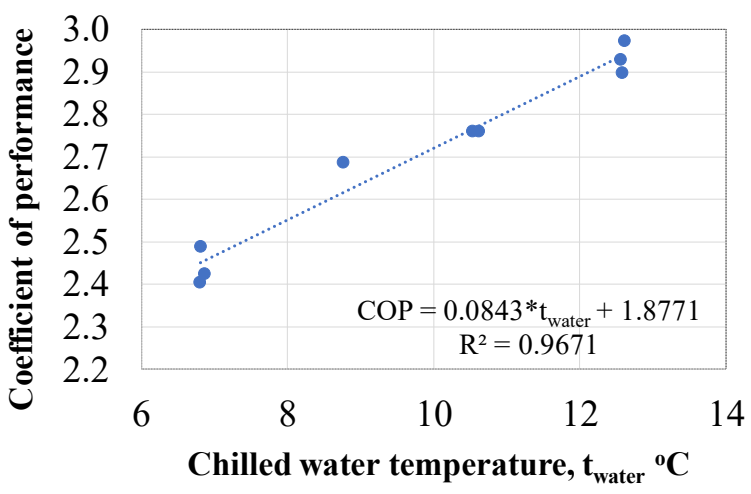

Fig. 3. Relationship between chilled water temperature and the COP of the water chiller

If the chilled water temperature is $8{ }^{\circ} \mathrm{C}$, the $\mathrm{COP}$ is 2.55 . If the chilled water temperature is $12{ }^{\circ} \mathrm{C}$, the COP is 2.89 , an increase of $13 \%$. The increase of the COP can be explained by the increase of the evaporation pressure. The latter leads to the increase of the heat absorbed by evaporator $q_{0}$ and the decrease of the work of the compression process. Consequently, the COP increase $13 \%$ whilst the chilled water temperature increases only $4 \mathrm{~K}$. This is a good hint which can help to optimize the system during the design process or to optimize the operating conditions.

\section{CONCLUSIONS}

The experimental air-cooled water chiller has been designed and manufactured. The experimental set-up was integrated with the temperature and pressure sensors at important measuring points to determine the typical thermodynamic properties as well as to 
calculate the energy performance of main equipment and the system. The measuring instrument has been calibrated by a national certified calibration organization. The calibrate results show that the uncertainty of the measured temperature at $95 \%$ confidence level is $0.12{ }^{\circ} \mathrm{C}$. The uncertainty of the measured pressure at $95 \%$ confidence level is $0.4 \%$, equivalent to $1.4 \mathrm{kPa}$.

The energy conversion efficiency of the R134a air-cooled water chiller working at a condensation temperature of $48.05^{\circ} \mathrm{C}$ and evaporation temperature of $3.17^{\circ} \mathrm{C}$ is 2.69 .

The energy conversion efficiency of the R134a water chiller system is highly dependent on the chilled water temperature. When the chilled water temperature increases $4 \mathrm{~K}$, from $8{ }^{\circ} \mathrm{C}$ to $12{ }^{\circ} \mathrm{C}$, the COP increases $13 \%$. The increase of the chilled water temperature can help to increase the COP. However, when the chiller water temperature increase, the evaporation pressure increases. The later causes the increment of the power consumption of the compressor, which drags the energy conversion efficiency of the system down. The opposite of the mentioned trend of energy performance can lead to having an optimal point for a certain application. Therefore, further study on looking for optimal operation condition for a certain application is interesting.

\section{ACKNOWLEDGMENT}

This research was funded by Vietnam National Foundation for Science and Technology Development (NAFOSTED) under grant number 107.03-2016.10.

\section{REFERENCES}

[1] The World Bank. https://data.worldbank.org/indicator/SP.POP.TOTL, (2018).

[2] L. Pérez-Lombard, J. Ortiz, and C. Pout. A review on buildings energy consumption information. Energy and Buildings, 40, (3), (2008), pp. 394-398. https://doi.org/10.1016/j.enbuild.2007.03.007.

[3] Z. Ma and S. Wang. Energy efficient control of variable speed pumps in complex building central air-conditioning systems. Energy and Buildings, 41, (2), (2009), pp. 197-205. https://doi.org/10.1016/j.enbuild.2008.09.002.

[4] F. W. Yu, W. T. Ho, K. T. Chan, and R. K. Y. Sit. Critique of operating variables importance on chiller energy performance using random forest. Energy and Buildings, 139, (2017), pp. 653-664. https://doi.org/10.1016/j.enbuild.2017.01.063.

[5] Z. Ma and S. Wang. An optimal control strategy for complex building central chilled water systems for practical and real-time applications. Building and Environment, 44, (6), (2009), pp. 1188-1198. https://doi.org/10.1016/j.buildenv.2008.08.011.

[6] S. Wang, D.-C. Gao, Y. Sun, and F. Xiao. An online adaptive optimal control strategy for complex building chilled water systems involving intermediate heat exchangers. Applied Thermal Engineering, 50, (1), (2013), pp. 614-628. https://doi.org/10.1016/j.applthermaleng.2012.06.010.

[7] A. N. Lai. THEPROPER1.10.02 Thermodynamic properties of fluids for science and engineering version 1.10.02. Vietnam Journal of Science, Technology and Engineering, 84, (2011), pp. 80-84.

[8] TCVN 9595-3:2013. Uncertainty of measurement Part 3: Guide to the expression of uncertainty in measurement (GUM:1995).

[9] AHRI Standard 550/590. Standard for performance rating of water-chilling and heat pump waterheating packages using the vapor compression cycle, (2015). 
Phan Thi Thu Huong, Hoang Mai Hong, Lai Ngoc Anh 